\section{The effect of deprivation upon fixed-interval responding: A two-state analysis*}

\author{
ROBERT W. POWELL \\ University of South Florida, Tampa, Fla. 33620
}

Responding under fixed-interval schedules was studied in three pigeons as a function of three deprivation procedures. Postreinforcement pauses and response rate were measured separately, and quarter-life values were determined. The terminal performance for each bird was characterized by break-and-run patterns of response. Chronic changes in body weight of $5 \%$ to $10 \%$ of the bird's free-feeding weight systematically influenced response rates, but postreinforcement pauses and quarter-life values did not change. Neither prefeeding nor acute periods of deprivation up to $72 \mathrm{~h}$ resulted in consistent changes in any of the dependent measures. Deprivation primarily influences postreinforcement pausing under fixed-ratio schedules, while response rate is unaffected. Thus deprivation appears to influence behavior differentially under the two schedules.

Fixed-interval (FI) schedules require that a fixed time period elapse, after which the first response is reinforced. Under fixed-ratio (FR) schedules, reinforcement is presented when a specified number of responses have been emitted. Two distinct response patterns have emerged under FI schedules: (1) a break-and-run pattern in which a pause follows reinforcement, and then a constant rate of response until the next reinforcement is obtained (Cumming \& Schoenfeld, 1958; Sherman, 1959; Schneider, 1969), and (2) a so-called scallop pattern of responding, in which rate is a gradually increasing function of time since reinforcement (Keller \& Schoenfeld, 1950; Ferster \& Skinner, 1957; Dews, 1962). Fixed-ratio schedules have invariably produced break-and-run patterns, providing the response requirement was not too large (Ferster \& Skinner, 1957).

Changes in deprivation seem to affect the duration of the postreinforcement pause to a much greater extent than they do the response rate under $\mathrm{FR}$ schedules (Sidman \& Stebbins, 1954; Malott, 1966; Powell, 1969). Weiss \& Moore (1956) studied responding under FI schedules in two groups of rats after 5 and $22 \mathrm{~h}$ of food deprivation. The authors observed an overall increase in response rate at the higher deprivation level, but the distribution of responses between reinforcements was not significantly altered.

The present experiment studied the influence of food deprivation upon FI behavior. Postreinforcement pauses

* Reprints may be obtained from the author, Department of Interdisciplinary Social Science, University of South Florida, Tampa, Fla. 33620. in body weight, (3) prefeeding. reinforcement. Reinforcement times were 2.5 (Bird 33) and $3.0 \mathrm{sec}$ (Birds 16 and 20). During reinforcement, the keylight was turned off. All scheduling was accomplished by standard relay circuitry. Data were recorded by digital counters, a Gerbrands cumulative recorder, and a Grason-Stadler multiple class time analyzer, No. E3905A, the latter being used to quantify the distribution of responses between reinforcements. \section{PROCEDURE}

The following definitions will apply throughout this experiment: (1) postreinforcement pause-the time from the end of the reinforcement period until the first response; (2) response rate-responses per unit of time from the first response after reinforcement until the final response which produces food; (3) overall response rate-total session responses, divided by total session time, less reinforcement time (postreinforcement pause and response rate are considered as a unit); (4) quarter-life-the time taken, in the interval between reinforcements, for the first $25 \%$ of the total number of responses to be emitted (Herrnstein \& Morse, 1957).

Each bird was trained first under a FI 2-min schedule. Body weights during training were approximately $87 \%$ of each animal's free-feeding weight. Training sessions, which were $90 \mathrm{~min}$ in duration, continued until stable performance developed. Stability was defined according to the following two criteria throughout the experiment: (1) variation in the overall response rate of $\pm 10 \%$ or less of the mean rate over 10 consecutive sessions, and (2) variation in quarter-life values over a range of $10 \%$ or less over 10 consecutive sessions, i.e., the largest quarter life could not exceed the smallest by more than $10 \%$.

When the study of performance

Table 1

The Sequence of Experimental Procedures for Each Bird*

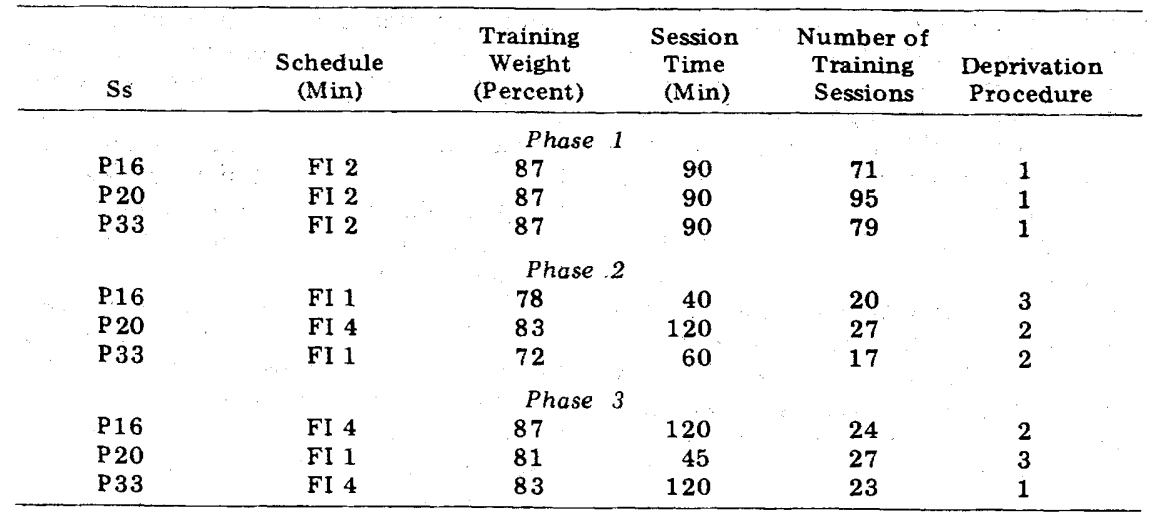

*The training weight is based upon the final 10 sessions prior to variations in deprivation. The deprivation procedures are identified as follows: (1) hours deprived, (2) changes 

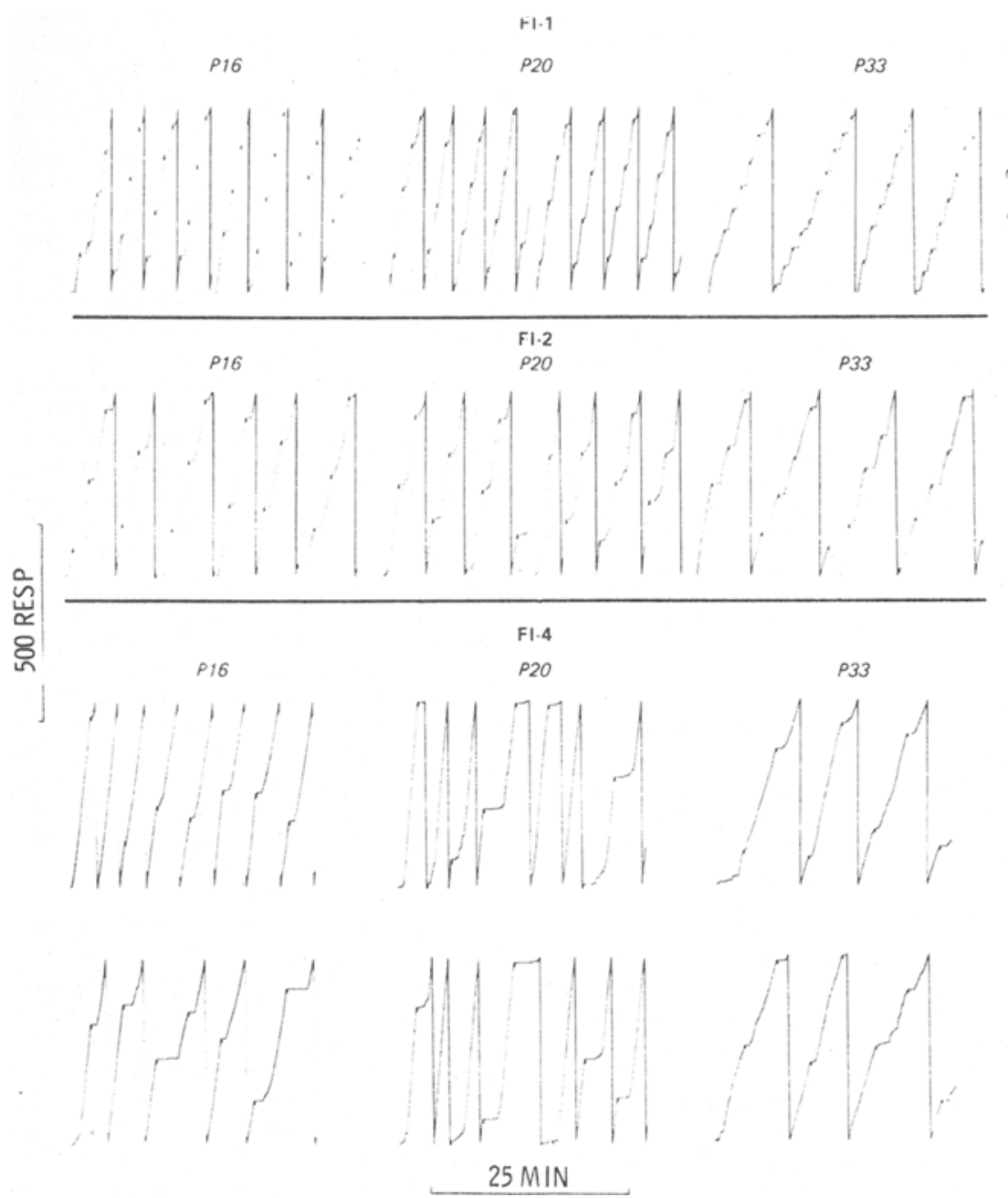

Fig. 1. Representative cumulative records for each pigeon at each FI value. The records were selected from among the final 10 training sessions, prior to changes in deprivation. The downward slashes indicate the delivery of food.

under FI 2 was completed, Birds 16 and 33 were studied next under FI 1 and FI 4-min schedules, in succession. For Bird 20, the sequence was reversed. In each case, the bird was trained until stable performance was achieved under the new schedule, and then deprivation was manipulated. Variations in deprivation were accomplished through the following procedures, which were employed during successive phases of the experiment.

(1) Hours of Food Deprivation. Food was withheld for 24,48 , or $72 \mathrm{~h}$ prior to the experimental sessions. The sequence of deprivation periods was generally as follows: $72,24,48,24 \mathrm{~h}$. The birds were given supplemental feeding after each session in order to keep body weight at the same level as during training. The number of sessions under each condition was as follows: Bird 16 (FI 2)-24 h (13), $48 \mathrm{~h}$ (7), $72 \mathrm{~h}$ (7); Bird 20
(FI 2)-24 h (14), $48 \mathrm{~h} \mathrm{(9),} 72 \mathrm{~h} \mathrm{(9);}$ Bird 33 (FI 2) $-24 \mathrm{~h}$ (11), $48 \mathrm{~h}$ (8), $72 \mathrm{~h} \mathrm{(6);} \mathrm{Bird} 33$ (FI 4)-24 h (15), $48 \mathrm{~h}(15), 72 \mathrm{~h} \mathrm{(10)}$.

(1) Systematic changes in body weight. Ten experimental sessions were conducted at each weight level. Changes in weight were accomplished through reduced or supplemental feeding each day for 5 to 7 days. Succeeding weight levels differed by $5 \%$ to $10 \%$ of the animal's free-feeding weight. There was approximately a 24-h period of food deprivation prior to each session.

(3) Prefeeding. The birds were fed $0,5,10$, or $15 \mathrm{~g}$ of mixed grain $1 \mathrm{~h}$ prior to the experimental session. The prefeeding sequence varied unsystematically. The number of sessions under each condition was as follows: Bird 16 (FI 1) $-0 \mathrm{~g}$ (13), $5 \mathrm{~g}$ (10), $10 \mathrm{~g} \mathrm{(9),} 15 \mathrm{~g}$ (10); Bird 20 (FI 1) $0 \mathrm{~g}(12), 5 \mathrm{~g}(8), 10 \mathrm{~g}(8), 15 \mathrm{~g}$ (7).
The experimental schedule is shown for each bird in Table 1.

Representative cumulative records, which appear in Fig. 1, show that break-and-run patterns of response were predominant under each FI schedule when performance was stable for each bird. When acceleration of responding occurred during the interval, the terminal response rate was usually achieved very quickly. This transitional period of responding (from zero to the maximal rate achieved) appeared to increase in duration as the FI time increased. However, there was no case where response rate could be characterized as a gradually increasing function of the time since reinforcement (scalloping). Bird 33 frequently showed a decrease in responding just prior to reinforcement under each FI schedule. This response pattern is not unusual under FI schedules (Ferster \& Skinner, 1957) and may be a function of anticipatory movements toward the grain hopper as the end of the interval approaches.

Deprivation effects were analyzed first on the basis of the procedure employed. Systematic changes in body weight (Procedure 2) resulted in higher response rates (measured separately) as weight decreased, and lower rates as weight increased, as shown in Fig. 2. The only exceptions are found in the data for Bird 33, where there was a marked increase in rate when weight increased from $72 \%$ to $79 \%$ and then no change in rate when weight increased to $86 \%$.

Kruskal-Wallis analyses of variance, which were performed on the response rate data for each bird across the series of sessions in which weight was either decreasing or increasing, showed statistically significant differences in every case $(p<.01)$. The results for Bird 33 at $72 \%$ body weight were excluded from the analysis because they deviated substantially from the trend. The other two dependent measures, postreinforcement pausing and quarter-life, did not show any consistent relationship to deprivation.

When deprivation time prior to the session was varied (Procedure 1), response rates were relatively stable, except that Bird 20 showed a slight increase in rate as deprivation increased. Fig. 3 shows also that postreinforcement pausing and quarter-life were generally stable across deprivation conditions.

Kruskal-Wallis analyses revealed that none of the differences in the dependent measures were statistically significant. Fig. 4 presents the results for the two birds which were studied with variations in prefeeding amounts. This procedure had no discernible influences on any of the three 


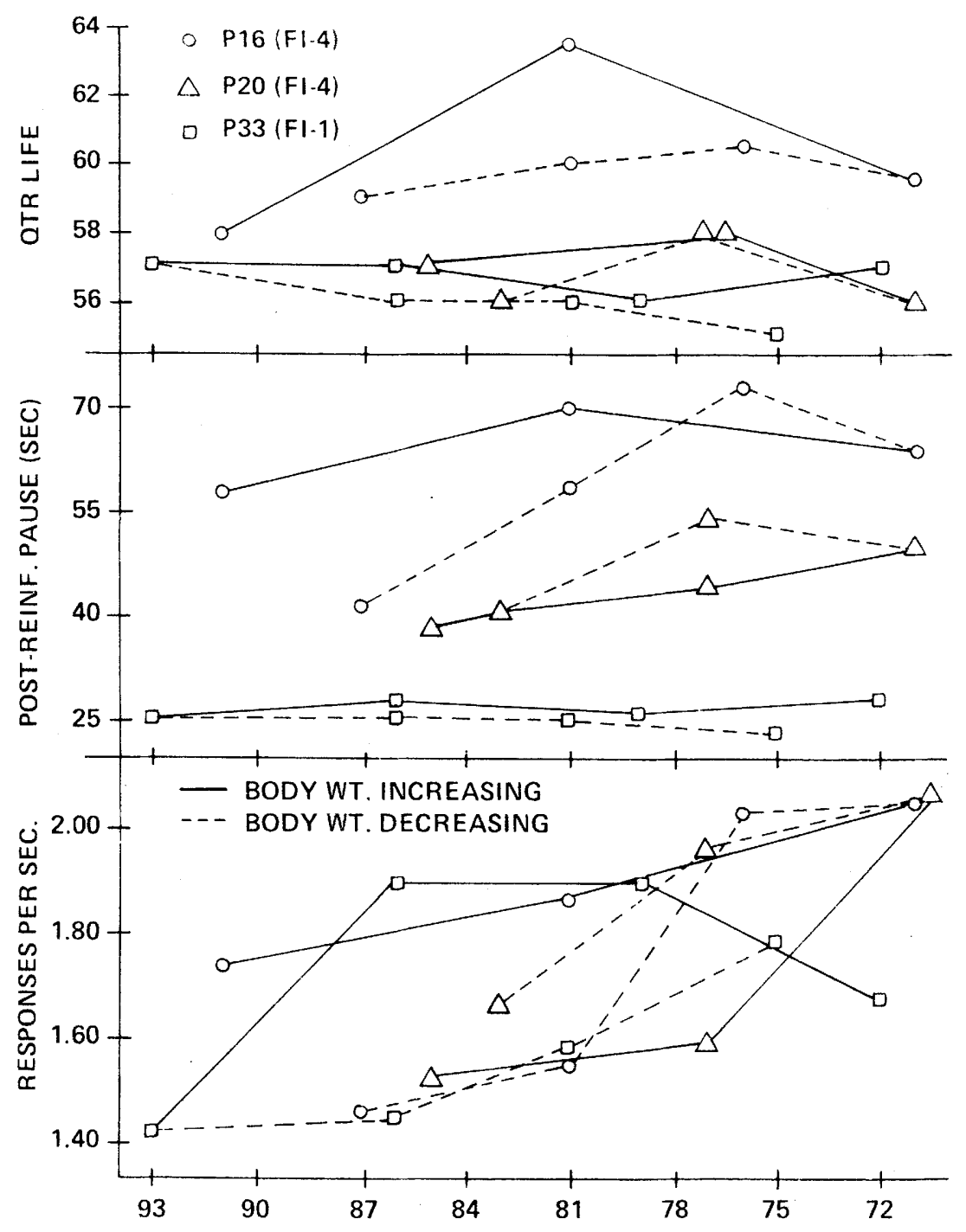

PERCENT OF FREE.FEEDING WEIGHT

Fig. 2. The mean performance for each bird with systematic changes in body weight. Response rates and postreinforcement pauses were measured separately. Data points relating to the series of sessions over which body weight decreased are connected by dashed lines, while those relating to sessions over which body weight increased are connected by solid lines. The data points have been connected in the same sequence that the weight values were studied during the experiment. Each data point represents the mean performance over 10 sessions.

dependent measures, and all Kruskal-Wallis tests were not significant.

\section{DISCUSSION}

The principle finding was that fixed-interval responding was sensitive to only one of the three deprivation procedures studied here. Changes of $5 \%$ to $10 \%$ in the animal's body weight were necessary in order to produce significant changes in performance. Acute periods of deprivation up to $72 \mathrm{~h}$ and prefeeding up to $15 \mathrm{~g}$ of food $1 \mathrm{~h}$ prior to the session had negligible effects upon responding. When deprivation did produce a change, it observed under FR schedules, while ratio response rate did not show similar relationships (Sidman \& Stebbins, 1954; Malott, 1966; Powell, 1969).

The effect of experience upon deprivation must be considered in an experiment such as this, where there are repeated cycles of deprivation and recovery. However, most studies have shown that prior exposure to deprivation does not seem to facilitate adaptation to subsequent deprivation schedules (Ghent, 1951; Lawrence \& Mason, 1955; Beck, 1962; Fallon, 1965; Tang \& Collier, 1971). None of the birds in the present study showed changes in performance which were correlated with the amount of

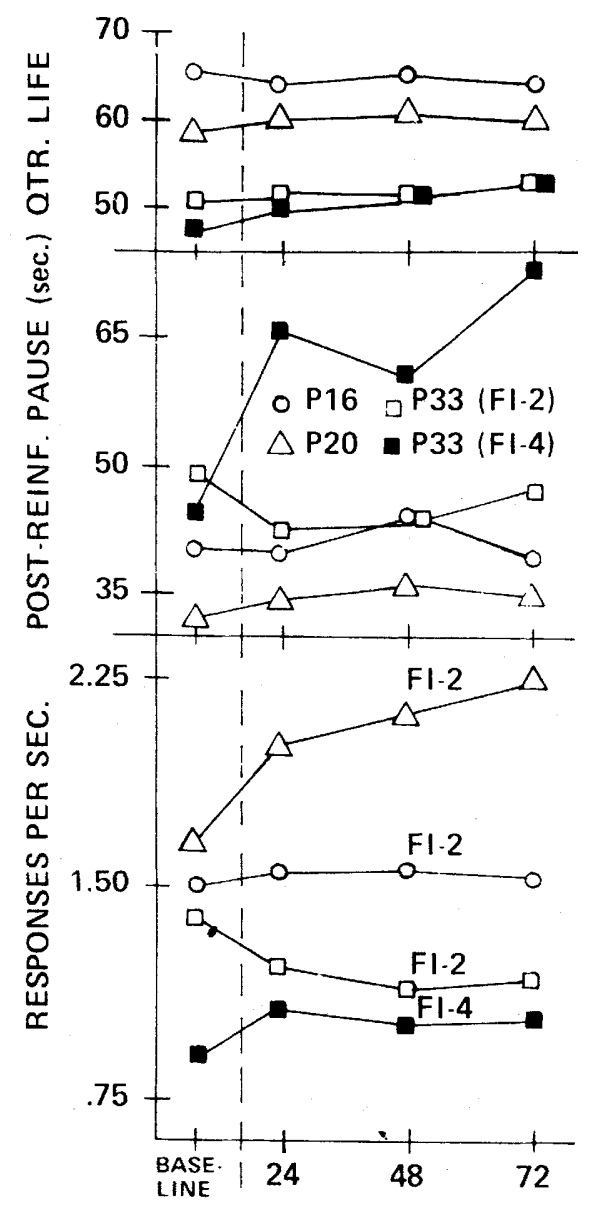

HRS. OF DEPRIVATION

Fig. 3. The mean performance for each bird as a function of the number of hours of food deprivation prior to the experimental session. This procedure was employed with Bird 33 under both FI-2 and FI-4 schedules. Response rate and postreinforcement pauses were measured separately. Data points corresponding to baseline on the abscissa represent the mean performance over 10 sessions. 
exposure to deprivation. The procedure which resulted in changes in performance was the third, second, and second in the sequence of three procedures for Birds 16, 20, and 33, respectively.

Weiss \& Moore (1956) found that rats on a FI 3-min schedule responded at much higher rates following $22 \mathrm{~h}$ as compared to $5 \mathrm{~h}$ of food deprivation. These animals seem to have been more susceptible to the influence of deprivation than the pigeons studied here, but a number of differences between the two experiments limit direct comparisons. Aside from the species difference, Weiss and Moore trained their rats for relatively brief periods $(250 \mathrm{~min})$, as compared to over $100 \mathrm{~h}$ of training for each bird here, prior to changes in deprivation. Since the development of break-and-run vs scalloped patterns of response may be a function of the amount of exposure to the FI schedule (Schneider, 1969), a major difference could have existed in this respect. Break-and-run response patterns predominated for each pigeon in the present experiment, whereas Weiss and Moore reported that response rate accelerated from the beginning to the end of the interreinforcement period. This effect was derived from averaged data and may be artifactual, however. Sidman (1952) has shown that a continuous curve can be obtained from averaging several discontinuous ones, providing the discontinuities do not overlap. Therefore, averaging techniques may misrepresent response patterns under FI schedules.

Responding under VI schedules has also been found to be relatively insensitive to the effects of deprivation (Powell, 1971). The limited effects of deprivation upon behavior under interval schedules may occur because rate of reinforcement is nearly independent of response rate under these schedules. Providing some minimal response rate occurs, all of the available reinforcements will be obtained. The effect of a variable upon responding depends largely upon how the response affects the rate of delivery of the variable (Rachlin, 1967; Neuringer, 1967). Similarly, Powell (1970) found that VI responding was more resistant to suppression by punishment than responding under a VR schedule. This

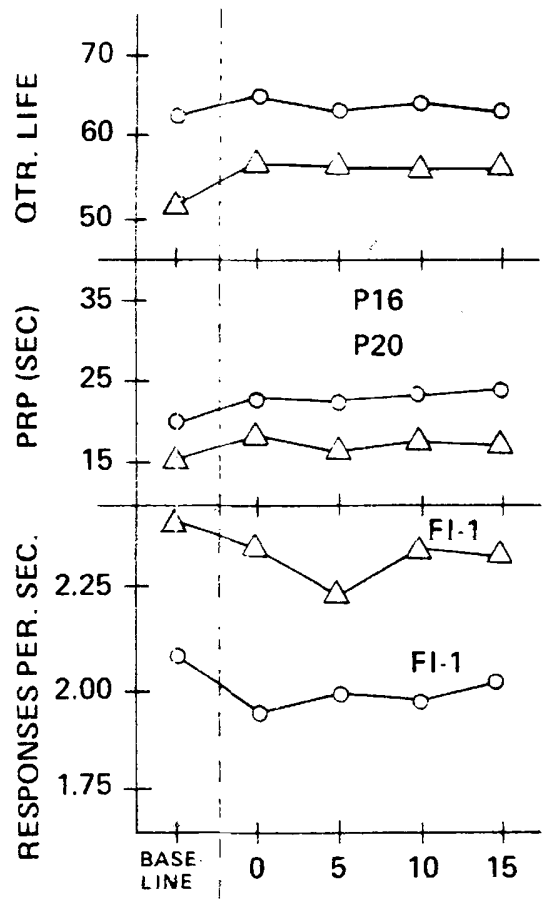

post-reinforcement pause length and running rate on fixed-interval pacing reinforcement schedules. Psychonomic Science, 1971, 23, 371-372.

FALLON, D. Effects of cyclic deprivation upon consummatory behavior: The role of deprivation history. Journal of Comparative \& Physiological Psychology, $1965,60,283-287$.

FERSTER, C. B., \& SKINNER, B. F. Schedules of reinforcement. New York: Appleton-Century-Crofts, 1957.

GHENT, $L$. The relation of experience to the development of hunger. Canadian Journal of Psy chology, 1951, 5, 77-81.

HERRNSTEIN, R. J.. \& MORSE, W. H. Effects of pentobarbital on intermittently reinforced behavior. Science, 1957,125 . 929-931.

KELLER, F. S., \& SCHOENFELD, W. N. Principles of psychology. New York: Appleton-Century-Crofts, 1950.

LAWRENCE, D. \& MASON,W. Intake and weight adjustments in rats to changes in feeding schedules. Journal of Comparative \& Physiological Psychology, $1955,48,43-46$.

MALOTT, R. W. The effects of prefeeding in plain and chained fixed ratio schedules of reinforcement. Psychonomic Science, $1966,4,285-286$.

NEURINGER, A. J. Effects of reinforcement magnitude on choice and rate of responding. Journal of the Experimental Analy sis of Behavior, 1967. $10,417-424$.

POWELL, $R$. W. The effect of deprivation upon fixed ratio responding. Psychonomic Science, 1969, 16, 17-18.

POWELL, R. W. The effect of punishment shock intensity upon responding under multiple schedules. Journal of the Experimental Analysis of Behavior, 1970 , 14, 201-211.

Fig. 4. The mean performance for each bird as a function of the amount of food given prior to the experimental session. Response rate and postreinforcement pauses were measured separately. Data points corresponding to baseline on the abscissa represent the mean performance over 10 sessions.

result was attributed to the slight decrease in reinforcement rate that occurs as VI responding decreases, whereas reinforcement rate changes in direct proportion to response rate under VR schedules.

\section{REFERENCES}

BECK, $R$. C. The rat's adaptation to $23.5 \mathrm{hr}$ water deprivation schedule. Journal of Comparative \& Physiological Psychology. $1962,55,646-648$.

CUMMING, W. W., \& SCHOENFELD, W. N. Behavior under extended exposure to a high-value fixed interval schedule. Journal of the Experimental Analysis of Behavior. $1958,1,245-263$

DEWS, P. B. The effect of multiple $\mathrm{s}^{\Delta}$ periods on responding on a fixed interval schedule. Journal of the Experimental Analysis of Behavior, 1962, 5, 369-374. ELSMORE, T. F. Independence of
POWELL, R. W. Effects of deprivation and prefeeding on variable interval responding. Psychonomic Science, 1971. $25,141-142$.

RACHLIN, H. The effect of shock intensity on concurrent and single-key responding in concurrent-chain schedules. Joumal of the Experimental Analysis of Behavior, $1967,10,87-93$.

SCHNEIDER, B. A. A two-state analysis of fixed interval responding in the pigeon. Journal of the Experimental Analysis of Behavior, 1969, 12,677-687.

SHERMAN, J. G. The temporal distribution of responses on fixed interval schedules. Unpublished doctoral dissertation, Columbia University, 1959.

SIDMAN, M. A note on functional relations obtained from group data. Psychological Bulletin, 1952, 49, 263-269.

SIDMAN, M., \& STEBBINS, W. C. Satiation effects under fixed ratio schedules of reinforcement. Journal of Comparative \& Physiological Psychology, 1954, 47. $114-116$.

TANG, M., \& COLLIER, G. Effect of successive deprivations and recoveries on the level of instrumental performance in the rat. Journal of Comparative \& Physiological Psychology, 1971, 74, 108-114.

WEISS, B., \& MOORE, E. W. Drive level as a factor in distribution of responses in fixed interval reinforcement. Journal of Experimental Psychology, 1956, 52, 82-84. 